\title{
Preoperative Inflammation Markers and De Ritis Ratio in Predicting Clinical Presentation and Prognosis of Patients with Testicular Germ Cell Tumors
}

\author{
Mahmut Taha Olcucu, Kaan Karamik, Kayhan Yilmaz, Yahya Okuducu, Serdar Cakir and Mutlu Ates \\ Department of Urology, University of Health Sciences, Antalya Training and Research Hospital, Antalya, Turkey
}

\begin{abstract}
Objective: To evaluate the importance of neutrophil-to-lymphocyte ratio (NLR), lymphocyte-to-monocyte ratio (LMR), platelet-to-lymphocyte ratio (PLR), neutrophil-to-monocyte ratio (NMR) and De Ritis ratio (DRR) in predicting clinical presentation and prognosis of patients with testicular germ cell tumors (TGCTs).

Study Design: Observational study.

Place and Duration of Study: Antalya Training and Research Hospital Antalya, Turkey, from January 2009 to March 2020.

Methodology: The characteristics and the results of biochemical and pathological examinations of patients who underwent radical orchiectomy were recorded. NLR, LMR, PLR, NMR, and DRR were calculated. The relationship among inflammation markers and DRR and clinical presentation and prognosis of TGCT was evaluated.

Results: Data of 99 patients were eligible for the study. Median age was 32 (27-39) years. Average size of the tumor was 5 (2.7 7) $\mathrm{cm}$. Average duration of follow-up was 35.4 (8-62) months. Higher NLR and lower LMR were significantly correlated with higher rates of advanced-stage cancer, metastasis, and retroperitoneal lymph node invasion (RPLNI) $(p<0.05)$. Based on the optimal cutoff values, there was a significantly higher rate of S stage, RPLNI, and metastatic disease in the high NLR group $(p<0.05)$. KaplanMeier survival analysis found a statistically significantly lower mean survival rate in the high NLR group $(p<0.05)$. There was no statistically significant difference between the DRR groups in the above-mentioned parameters $(p>0.05)$.

Conclusion: Preoperative NLR can be used as an inexpensive and easily accessible marker to predict clinical presentation at diagnosis and mortality rates during follow-up of patients with TGCT. Preoperative LMR can also be associated with the clinical picture at the time of diagnosis of TGCT.
\end{abstract}

Key Words: De ritis ratio, Lymphocyte-to-monocyte ratio, Neutrophil-to-lymphocyte ratio, Neutrophil-to-monocyte ratio, Platelet-to-lymphocyte ratio, Testicular germ cell tumor.

How to cite this article: Olcucu MT, Karamik K, Yilmaz K, Okuducu Y, Cakir S, Ates M. Preoperative Inflammation Markers and De Ritis Ratio in Predicting Clinical Presentation and Prognosis of Patients with Testicular Germ Cell Tumors. J Coll Physicians Surg Pak 2020; 30(10):1041-1046.

\section{INTRODUCTION}

Testicular cancer (TCa) is the most common solid tumor among men aged 15 to 44 years. ${ }^{1}$ Testicular germ cell tumors (TGCTs) constitute the majority of all testicular tumors. ${ }^{2}$ TGCTs are divided into two main types as seminomatous and non-seminomatous. The majority of patients with non-seminomatous germ cell testicular tumors (NSTGCTs) have elevated levels of either alpha-fetoprotein (AFP) or beta-human chorionic gonadotropin $(\beta-h C G){ }^{3}$ However, about half of the patients have a combined increase in AFPand $\beta$-hCG levels.

Correspondence to: Dr. Mahmut Taha Olcucu, Department of Urology, University of Health Sciences, Antalya Training and Research Hospital, Antalya, Turkey

E-mail:matah_ol@hotmail.com

Received: August 18, 2020; Revised: September 27, 2020;

Accepted: October 06, 2020

DOI: https://doi.org/10.29271/jcpsp.2020.10.1041
Moreover, about a third of seminoma patients have elevated $\beta$ hCG levels. Lactate dehydrogenase (LDH) levels may increase in cases with metastasis. Radical orchiectomy is used for the surgical treatment of patients with TCa.

Inflammation is known to be of critical importance in cancer development. ${ }^{4}$ Inflammation markers such as neutrophils, lymphocytes, monocytes and platelets, the levels of which can be evaluated by complete blood count, which is an inexpensive method, are frequently used in daily medical practice. In recent years, there is an increasing number of studies examining neutrophil-to-lymphocyte (NLR), neutrophil-to-monocyte (NMR), lymphocyte-to-monocyte (LMR), platelet-to-lymphocyte $(P L R)$ ratios to examine the relationship between inflammation and cancer.

Aspartate transaminase (AST) and alanine transaminase (ALT) are liver enzymes and their levels are increased in the case of hepatocellular injury. ${ }^{5}$ De Ritis ratio (DRR) was first defined in 1957 as the ratio of AST to $\mathrm{ALT} .{ }^{6}$ Although DRR increases in the 
case of viral hepatitis, the studies demonstrated its association with a wide variety of cancer types, including Tca. ${ }^{7-11}$

Table l: Patients' characteristics.

\begin{tabular}{|c|c|}
\hline$n=99$ & Median (IQR) \\
\hline Age (years) & $32(27-39)$ \\
\hline $\operatorname{AFP}(\mu \mathrm{g} / \mathrm{L})$ & $5.15(2.26-217)$ \\
\hline BHCG (U/L) & $6.8(1.1-64.6)$ \\
\hline $\mathrm{LDH}(\mathrm{U} / \mathrm{L})$ & $249(198-395)$ \\
\hline $\operatorname{ALT}(\mathrm{U} / \mathrm{L})$ & $20(15-30)$ \\
\hline AST (U/L) & $23(19-28)$ \\
\hline WBC $\left(10^{3} / \mathrm{mm}^{3}\right)$ & $8400(7300-10100)$ \\
\hline Platelet $\left(10^{3} / \mathrm{mm}^{3}\right)$ & $258000(217000-318000)$ \\
\hline Neutrophil $\left(10^{3} / \mathrm{mm}^{3}\right)$ & $5300(4300-6800)$ \\
\hline Lymphocyte $\left(10^{3} / \mathrm{mm}^{3}\right)$ & $2100(1600-2600)$ \\
\hline Monocyte $\left(10^{3} / \mathrm{mm}^{3}\right)$ & $700(500-900)$ \\
\hline DRR & $1.1(0.86-1.36)$ \\
\hline NLR & $2.48(1.81-3.87)$ \\
\hline PLR & $120.48(100.9-167.5)$ \\
\hline LMR & $3(2-4)$ \\
\hline NMR & $7.67(6.4-9.20)$ \\
\hline \multicolumn{2}{|l|}{ Tumor type $n(\%)$} \\
\hline Classical seminoma & $45(45.5)$ \\
\hline Mixed germ cell tumor & $41(41.4)$ \\
\hline Embryonal carcinoma & $9(9.1)$ \\
\hline Yolk-sac tumor & $2(2)$ \\
\hline Teratoma & $1(1)$ \\
\hline Choriocarcinoma & $1(1)$ \\
\hline Tumor size $(\mathrm{cm})$ & $5(2.7-7)$ \\
\hline \multicolumn{2}{|l|}{ T stage $n(\%)$} \\
\hline $\mathrm{T1}$ & $44(44.4)$ \\
\hline T2 & $45(45.5)$ \\
\hline T3 & $9(9.1)$ \\
\hline T4 & $1(1)$ \\
\hline LVI (\%) & $48(48.5)$ \\
\hline \multicolumn{2}{|l|}{ S stage $n(\%)$} \\
\hline S0 & 61 (61.6) \\
\hline S1 & $28(28.3)$ \\
\hline S2 & $5(5.1)$ \\
\hline S3 & $5(5.1)$ \\
\hline RPLNI $\mathrm{n}(\%)$ & $37(37.4)$ \\
\hline \multicolumn{2}{|l|}{$\mathrm{N}$ stage $\mathrm{n}(\%)$} \\
\hline N0 & $62(62.6)$ \\
\hline N1 & $9(9.1)$ \\
\hline N2 & $12(12.1)$ \\
\hline N3 & $16(16.2)$ \\
\hline Metastasis $\mathrm{n}(\%)$ & $19(19.2)$ \\
\hline \multicolumn{2}{|l|}{ M stage $\mathrm{n}(\%)$} \\
\hline M0 & $80(80.8)$ \\
\hline M1a & $9(9.1)$ \\
\hline M1b & $10(10.1)$ \\
\hline \multicolumn{2}{|l|}{ Stage grouping $\mathrm{n}(\%)$} \\
\hline $1 \mathrm{~A}$ & $27(27.3)$ \\
\hline 1B & $20(20.2)$ \\
\hline 15 & $9(9.1)$ \\
\hline $2 \mathrm{~A}$ & $5(5.1)$ \\
\hline $2 \mathrm{~B}$ & $12(12.1)$ \\
\hline $2 \mathrm{C}$ & $7(7.1)$ \\
\hline $3 \mathrm{~A}$ & $7(7.1)$ \\
\hline $3 \mathrm{~B}$ & $2(2)$ \\
\hline $3 \mathrm{C}$ & $10(10.1)$ \\
\hline Progression n(\%) & $22(22.2)$ \\
\hline Time to progression (months) & $16(6-46)$ \\
\hline Mortality n(\%) & $12(12.1)$ \\
\hline Time to death (months) & $9.5(1.25-48)$ \\
\hline Follow-up (months) & $30(8-62)$ \\
\hline \multicolumn{2}{|c|}{$\begin{array}{l}\text { AFP: Alpha-fetoprotein. ALT: Alanine aminotransferase. AST: Alanine aminotransferase. BHCG: } \\
\text { Beta-human chorionic gonadotropin, DRR: De Ritis ratio. LDH: Lactate dehydrogenase. LMR: } \\
\text { Lymphocyte-to-monocyte ratio. LVI: Lymphovascular invasion. NLR: Neutrophil-to-lymphocyte } \\
\text { ratio. NMR: Neutrophil-to-monocyte ratio. PLR: Platelet-to-lymphocyte ratio. RPLNI: } \\
\text { Retroperitoneal lymph node invasion. WBC: White blood cell. }\end{array}$} \\
\hline
\end{tabular}

The main objective of this study was to investigate the importance of NLR, NMR, LMR, PLR and DRR in predicting the clinical presentation and prognosis at the time of diagnosis of TGCTs.

\section{METHODOLOGY}

The study was conducted after approval from the Ethics Committee of Antalya Training and Research Hospital Antalya, Turkey. Patients who underwent orchiectomy for testicular cancer at the hospital between January 2009 and March 2020 were retrospectively analysed. The patients with non-testicular germ cell tumors, incomplete data or follow-up, chronic use of immunosuppressive drugs or hematological disease, and liverrelated diseases or liver metastases were excluded. Furthermore, the patients' age and preoperative laboratory results (AFP, $\beta$-hCG, ALT, AST, LDH, and blood cell counts, including white blood cells, neutrophils, lymphocytes, monocytes, and platelets), pathological examination results (size, type and histopathological features of the tumor), retroperitoneal lymph node invasion (RPLNI), distant metastasis status, progression and death, and follow-up time were recorded. Based on computed tomography and magnetic resonance imaging studies, lymph node involvement and distant metastasis status were evaluated. $\mathrm{S}$ stage was determined by measuring serum AFP, $\beta$-hCG and LDH levels in the second week after radical orchiectomy. TNM classification and Stage grouping were based on the 2016 Annual Report for the Union for International Cancer Control (UICC). ${ }^{12}$ Preoperative NLR, NMR, LMR, PLR and DRR values were calculated and noted.

The analysis of the data was conducted using SPSS Statistics version 25.0 (IBM, Corp., Armonk, NY). The qualitative data were presented as frequency and percentage, while the quantitative data were presented as mean (IQR). The normality distribution was tested by the Shapiro-Wilk test. Mann-Whitney Utest and Kruskal-Wallis test were used for the comparison between categorical and quantitative variables. The Bonferroni/Dunn test was used for post hoc comparison of significant variables. The Chi-Square test was used for the comparison of qualitative data. Receiver operating characteristic (ROC) analysis was performed to determine the role of variables in predicting mortality. Variables were categorised according to the cut-off values determined by ROC analysis. Survival curves were generated by using the Kaplan-Meier analysis and compared with the log-rank test. A p-value of less than 0.05 was considered statistically significant.

\section{RESULTS}

The data of 141 patients who underwent radical orchiectomy for suspected testicularcancer were analysed. Patients with non-TGCTs ( $n=18)$, incomplete data or follow-up $(n=12)$, chronic use of immunosuppressive drugs or a hematological disease $(n=9)$, and liver-related diseases or liver metastases $(n=3)$ were excluded. Data of 99 patients were eligible for the study. Patients' median age was 32 (27-39) years, median tumor size was 5 (2.7-7) cm, and median follow-up time was 30 (8-62) months. The rates of RPLNI and distant metastases were $37.4 \%$ and $19.2 \%$, respectively. Patients have been treated with chemotherapy or/and retroperitoneal lymph node dissection or/and radiotherapy according to their tumour stage. The characteristics of the patients are summarised in Table l. 


\begin{tabular}{|c|c|c|c|c|}
\hline & \multicolumn{4}{|l|}{ Stage grouping } \\
\hline & $\begin{array}{l}\text { Stage } 1(n=56) \\
\text { Median (IQR) }\end{array}$ & $\begin{array}{l}\text { Stage } 2(n=24) \\
\text { Median (IQR) }\end{array}$ & $\begin{array}{l}\text { Stage } 3(n=19) \\
\text { Median (IQR) }\end{array}$ & $\mathrm{p}$ \\
\hline DRR & $1.07(0.85-1.29)$ & $1.10(0.80-1.35)$ & $1.2(0.96-1.48)$ & 0.357 \\
\hline NLR & $2.2(1.66-3.07)^{\mathrm{a}}$ & $2.5(2.07-3.88)^{a, b}$ & $3.37(2.47-6.86)^{\mathrm{b}}$ & $0.002 *$ \\
\hline PLR & $113.88(89.17-156.42)$ & $133.17(105.89-177.20)$ & $128.57(106.47-224.4)$ & 0.085 \\
\hline LMR & $3.07(2.39-4.48)^{\mathrm{a}}$ & $2.82(2-4.15)^{a, b}$ & $2(1.4-3.16)^{b}$ & $0.024 *$ \\
\hline \multirow[t]{3}{*}{ NMR } & $7.53(6.23-8.83)$ & $8.27(6.45-10.59)$ & 7.72(1.14-13.5) & 0.359 \\
\hline & \multicolumn{4}{|l|}{ Metastasis } \\
\hline & $\begin{array}{l}\text { No }(n=80) \\
\text { Median (IQR) }\end{array}$ & $\begin{array}{l}\text { Yes }(n=19) \\
\text { Median (IQR) }\end{array}$ & \multicolumn{2}{|l|}{$\mathrm{p}$} \\
\hline DRR & $1.08(0.84-1.31)$ & $1.2(0.96-1.48)$ & \multicolumn{2}{|l|}{0.173} \\
\hline NLR & $2.37(1.73-3.43)$ & $3.38(2.48-6.87)$ & \multicolumn{2}{|l|}{$0.002^{*}$} \\
\hline PLR & 119.12(97.74-160.56) & 148.82(106.47-224.4) & \multicolumn{2}{|l|}{0.097} \\
\hline LMR & $3(2.26-4.15)$ & $2(1.40-3.17)$ & \multicolumn{2}{|l|}{$0.013^{*}$} \\
\hline \multirow[t]{3}{*}{ NMR } & $7.63(6.35-9.11)$ & $8.29(7.14-13.5)$ & \multicolumn{2}{|l|}{0.259} \\
\hline & \multicolumn{4}{|c|}{ Retroperitoneal lymph node invasion } \\
\hline & $\begin{array}{l}\text { No }(n=62) \\
\text { Median (IQR) }\end{array}$ & \begin{tabular}{|l|} 
Yes $(n=37)$ \\
Median (IQR) \\
\end{tabular} & \multicolumn{2}{|l|}{$\mathrm{p}$} \\
\hline DRR & $1.06(0.84-1.29)$ & $1.14(0.88-1.45)$ & \multicolumn{2}{|l|}{0.144} \\
\hline NLR & $2.22(1.66-3.13)$ & $2.83(2.27-4.93)$ & \multicolumn{2}{|l|}{$0.004^{*}$} \\
\hline PLR & $113.88(89.02-158.62)$ & 130.5(108.98-199.79) & \multicolumn{2}{|l|}{$0.028 *$} \\
\hline LMR & $3.07(2.38-4.43)$ & $2.33(1.59-3.62)$ & \multicolumn{2}{|l|}{$0.016^{*}$} \\
\hline NMR & $7.59(6.30-9.16)$ & $8.14(6.51-10.39)$ & \multicolumn{2}{|l|}{0.338} \\
\hline
\end{tabular}

Higher NLR were significantly correlated with higher rates of advanced-stage cancer, metastasis, and RPLNI ( $p=$ $0.002, p=0.002$ and $p=0.004$, respectively, Table II). Similarly, lower LMR were significantly correlated with higher rates of advanced-stage cancer, metastasis, and RPLNI ( $p=$ $0.024, p=0.013$ and $p=0.016$, respectively, Table II). Based on the optimal cut-off values, NLR and DRR were each divided into two groups, as high and low (Table III). LDH levels and tumor size were significantly higher in the high NLR group ( $p=0.003$ and $p=0.015$, respectively). Furthermore, there was a significantly higher rate of $\mathrm{S}$ stage, RPLNI, and metastatic disease in the high NLR group ( $p=0.023, p=0.015$ and $p=0.005$, respectively). However, there was no statistically significant difference between the high and low DRR groups ( $p>0.05$, Table III).

Kaplan-Meier analysis demonstrated significantly lower mean survival time in the high NLR group (77.41 months) compared to the low NLR group (96.18 months, $p=0.008$, Figure 1-A). There was no significant difference in mean survival time between the high DRR (86.17 months) and low DRR (96.23 months) groups ( $p=0.064$, Figure $1 B)$. Overall survival time was found as 91.53 months.

\section{DISCUSSION}

In the present study, it was concluded that NLR of $>3.219$ can be a diagnostic tool in predicting RPLNI at the time of diagnosis, presence of metastasis and positivity of serum markers after orchiectomy (S stage) in patients with TGCT. It has also been found that NLR of $>3.219$ may be associated with a high risk of long-term mortality.
Moreover, lower LMRs were significantly associated with higher rates of advanced-stage cancer, metastasis and RPLNI at the time of diagnosis. Based on the optimal cut-off value of 0.942 , DRR has not been proven to be a useful tool in predicting the clinical presentation and prognosis of TGCT. No optimal cut-off value could be established for NMR, LMR and PLR, which showed the absence of a significant relationship between these ratios and the clinical presentation and prognosis of TCGT. Lymphocytes are known to inhibit the proliferation and migration of tumor cells. ${ }^{13}$ Therefore, they have an important role in tumor immunity with antitumor effects. Studies on the prognostic value of NLR in TCa showed significantly higher NLR in patients with $\mathrm{TCa}$ compared to the control group. ${ }^{14-17}$ Arda et al. detected significantly higher NLR in the cancer group compared to the healthy non-operated varicocele group. However, NLR was not found to be significant in predicting tumor size, RPLNI and cancer-specific survival rate. ${ }^{14}$ Another study reported significantly higher NLRs in the cancer group. ${ }^{15}$ Furthermore, in a study with a higher number of participants reported significantly higher NLRs in the cancer group compared to the control group. ${ }^{16}$ Similar results were obtained in a study comparing patients with localised TCa and varicocele. ${ }^{17}$ This study included only patients with TGCT. Therefore, no comparison was made with the control group. However, this study concluded that NLR has promise as an alternative marker to $\beta$-hCG, AFP and LDH in predicting the clinical presentation of TGCT at the time of diagnosis.

Studies investigating the importance of NLR in predicting the prognosis of TGCT have obtained conflicting results. ${ }^{18-20}$ Ilktac et al. reported a significant decrease in NLR after orchiectomy in patients with localised TGCT. ${ }^{18}$ 


\begin{tabular}{|c|c|c|c|c|c|c|c|}
\hline \multicolumn{8}{|l|}{ Roc analysis } \\
\hline Mortality & Cut-off value & \multicolumn{2}{|c|}{ AUC $(95 \% \mathrm{Cl})$} & \multicolumn{2}{|c|}{ Sensitivity (\%) } & \multicolumn{2}{|l|}{ Specificity (\%) } \\
\hline DRR & $\geq 0.942$ & \multicolumn{2}{|c|}{$0.668(0.513-0.822)$} & \multicolumn{2}{|c|}{91.7} & \multicolumn{2}{|c|}{39.1} \\
\hline NLR & $\geq 3.219$ & \multicolumn{2}{|c|}{$0.705(0.541-0.868)$} & \multicolumn{2}{|l|}{66.7} & \multicolumn{2}{|l|}{73.6} \\
\hline LMR & $\leq 3.536$ & \multicolumn{2}{|c|}{$0.366(0.177-0.556)$} & \multicolumn{2}{|l|}{33.3} & \multicolumn{2}{|l|}{66.7} \\
\hline PLR & $\geq 178.33$ & \multicolumn{2}{|c|}{$0.589(0.405-0.772)$} & \multicolumn{2}{|l|}{41.7} & \multicolumn{2}{|l|}{82.8} \\
\hline NMR & $\geq 10.993$ & \multicolumn{2}{|c|}{$0.616(0.417-0.816)$} & \multicolumn{2}{|l|}{41.7} & \multicolumn{2}{|l|}{87.4} \\
\hline \multicolumn{8}{|l|}{ Progression } \\
\hline DRR & $\geq 0.942$ & \multicolumn{2}{|c|}{$0.556(0.423-0.688)$} & \multicolumn{2}{|l|}{77.3} & \multicolumn{2}{|l|}{39.0} \\
\hline NLR & $\geq 3.219$ & \multicolumn{2}{|c|}{$0.625(0.489-0.760)$} & \multicolumn{2}{|l|}{50} & \multicolumn{2}{|l|}{74.0} \\
\hline LMR & $\leq 3.536$ & \multicolumn{2}{|c|}{$0.460(0.306-0.613)$} & \multicolumn{2}{|l|}{36.4} & 67.5 & \\
\hline PLR & $\geq 178.33$ & $0.604(0.462-0$ & & 40.9 & & 85.7 & \\
\hline NMR & $\geq 10.993$ & $0.635(0.491-0$ & & 36.4 & & 89.6 & \\
\hline Comparison of pa & ents' characte & 5 according to $t$ & off values of $\mathrm{N}$ & DRR. & & & \\
\hline & & NLR & & & DRR & & \\
\hline & & Low $(n=68)$ & High $(n=31)$ & p-value & Low $(n=35)$ & High $(n=64)$ & p-value \\
\hline Age (years) & $\begin{array}{l}\text { Median } \\
\text { IQR }\end{array}$ & $\begin{array}{l}32 \\
27-38.5\end{array}$ & $\begin{array}{l}33 \\
25-39\end{array}$ & 0.818 & $\begin{array}{l}33 \\
29-39\end{array}$ & $\begin{array}{l}32 \\
26-38.75\end{array}$ & 0.639 \\
\hline & Median & 3.98 & 8.35 & 0152 & 5.15 & 5.27 & \\
\hline AFP $(\mu \mathrm{g} / \mathrm{L})$ & IQR & $2.20-137.2$ & $2.37-583.33$ & 0.152 & $2.37-77.8$ & $2.08-253$ & 0.930 \\
\hline & Median & 4.25 & 12.6 & & 2.5 & 8.4 & \\
\hline BHCG $(U / L)$ & IQR & $1.13-55.75$ & $1-133$ & 0.369 & $1-64.6$ & $1.35-67$ & 0.376 \\
\hline & Median & 223 & 337 & & 227 & 262.5 & \\
\hline LDH (U/L) & IQR & $194.25-302.5$ & $214-605$ & $0.003^{*}$ & $207-316$ & $191-438$ & 0.892 \\
\hline Tumarsiro $(\mathrm{cm})$ & Median & 4 & 6.3 & $0015 *$ & 4 & 5 & \\
\hline Tumor size (cm) & IQR & $2.5-6$ & $4-8$ & $0.015^{*}$ & $2.5-7$ & $2.78-7.5$ & 0.512 \\
\hline & Seminoma & $33(73.3)$ & $12(26.7)$ & & $16(35.6)$ & $29(64.4)$ & \\
\hline Tumor type & Non-Sem. & $35(64.8)$ & $19(35.2)$ & 0.363 & $19(35.2)$ & $35(64.8)$ & 0.969 \\
\hline & No (\%) & $35(68.6)$ & $16(31.4)$ & & $18(35.3)$ & $33(64.7$ & \\
\hline LVI & Yes (\%) & $33(68.8)$ & $15(31.2)$ & 0.990 & $17(35.4)$ & $31(64.6)$ & 0.990 \\
\hline & S0 (\%) & $47(77)$ & $14(23)$ & & $23(37.7)$ & $38(62.3)$ & \\
\hline S stage & $\mathrm{S} 1+2+3(\%)$ & $21(55.3)$ & $17(44.7)$ & $0.023^{*}$ & $12(31.6)$ & $26(68.4)$ & 0.535 \\
\hline & No (\%) & $48(77.4)$ & $14(22.6)$ & & $24(38.7)$ & $38(61.3)$ & \\
\hline RPLNI & Yes (\%) & $20(54.1)$ & $17(45.9)$ & $0.015^{*}$ & $11(29.7)$ & $26(70.3)$ & 0.366 \\
\hline & No $(\%)$ & $60(75)$ & $20(25)$ & & $31(38.8)$ & $49(61.2)$ & \\
\hline Metastasis & Yes (\%) & $8(42.1)$ & $11(57.9)$ & $0.005^{*}$ & $4(21.1)$ & $15(78.9)$ & 0.147 \\
\hline
\end{tabular}

They also reported that NLR was significantly higher in nonlocalised tumors than localised tumors and that NLR showed a decrease in the postoperative period in patients with and without an elevation in tumor markers. They also suggested that NLR can be used as a biomarker for the postoperative follow-up of patients with TGCT. Another study on NLR and the prognosis of TGCT found higher rates of residual disease, advanced-stage disease, and shorter survival in patients with higher NLR. ${ }^{19}$ In contrast to these studies, Bolat et al. could show no statistically significant difference between NLR and study parameters. ${ }^{20}$ Our study showed that NLR can be used to predict RPLNI at the time of diagnosis of TCGT and a potential increase in serum markers after radical orchiectomy. Moreover, it is found that patients with higher NLR had lower cancer-specific survival rates. Prospective studies and meta-analyses are needed to obtain clearer results on this subject.

There is an increasing number of studies on the use of LMR as a biomarker in cancer prognosis. ${ }^{21}$ In a meta-analysis investigating the value of LMR in non-hematological malignancies, Nishijima et al. showed that lower LMR may be associated with poor oncological outcomes. ${ }^{22}$

Similarly, a meta-analysis on the prognostic value of LMR in urological cancers showed a relationship between LMR and survival rate. ${ }^{23}$ However, this study did not include patients with TCa. Our study showed that lower LMR was significantly associated with higher rates of advanced-stage cancer, metastasis and RPLNI at the time of diagnosis. However, it is showed that there is no relationship between LMR and progression and mortality, which may be attributed to the relatively low number of patients in this study.

ALT and AST are markers that are frequently used in routine medical practice and reflect liver functions. Although DRR has previously been used to diagnose viral hepatitis, studies showed its association with different cancers. ${ }^{7-11}$ While ALT is an enzyme found in the cytoplasm of hepatocytes, AST is found in both the cytoplasm and mitochondria of hepatocytes. Moreover, AST is expressed in different organs. Increased turn-over in tumor cells causes a higher increase in AST levels compared to ALT levels due to cell damage. ${ }^{24}$ This has highlighted DRR as a potential biomarker. Two studies on the relationship between DRR and TCa reported that DRR can predict poor prognosis. ${ }^{9,10}$ However, the present study did not demonstrate a comparable relationship. Large scale further prospective studies will help clarify this issue. 


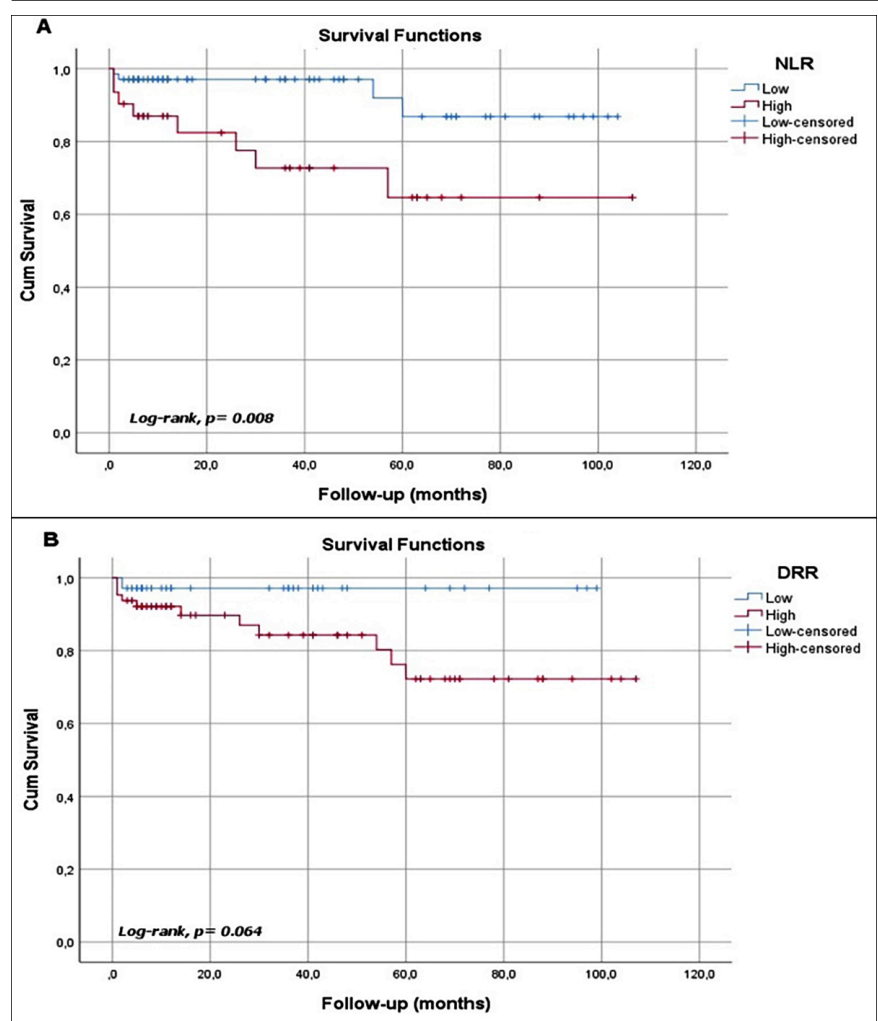

Figure 1: Demonstration of Kaplan-Meier survival curves according to the cut-off values of NLR and DRR. (A) High NLRs were significantly associated with decreased survival. (B) No association was found between DRR and survival.

DRR: De Ritis ratio. NLR: Neutrophil-to-lymphocyte ratio.

This study has some limitations, primarily it is a retrospective study design. Moreover, the low number of patients is another limitation of the study. Finally, special conditions such as smoking and metabolic syndrome that may affect the levels of inflammation markers have not been recorded.

\section{CONCLUSION}

Preoperative NLR can be used as an inexpensive and easily accessible marker to predict the stage of cancer, metastasis status and RPLNI at diagnosis and mortality rates during follow-up of patients with TGCT. There may also be a relationship between preoperative LMR and the stage of TGCT, metastasis status, and RPLNI at the diagnostic stage. Prospective multi-center studies with higher numbers of patients are needed to obtain more reliable results.

\section{CONFLICT OF INTEREST:}

Authors declared no conflict of interest.

\section{ETHICAL APPROVAL:}

Ethics Committee approval was received for this study from the Ethics Committee of Antalya Training and Research Hospital (approval date and No. 8/14 - 04.06.2020).

\section{AUTHORS' CONTRIBUTION:}

MTO: Conception, materials, data collection and analysis, writing, critical study.

KK: Conception, materials, writing.
KY: Materials, critical review.

YO, MA: Critical review.

SC: Data collection.

\section{REFERENCES}

1. Znaor A, Lortet-Tieulent J, Jemal A, Bray F. International variations and trends in testicular cancer incidence and mortality. Eur Urol 2014; 65(6):1095-1106. doi: 10.1016/ j.eururo.2013.11.004.

2. Albers P, Albrecht W, Algaba F, Bokemeyer C, Cedermark GC, Fizazi T, et al. EAU guidelines on testicular cancer: 2011 update. Eur Urol 2011; 60(2):304-19. doi: 10.1016/ j.eururo.2011.05.038.

3. Sattar A, Masood M, Nisar H, Fatima I, Shahid AB. Disease characteristics and treatment outcome of testicular germ cell tumors treated with platinum-based regimens. J Coll Physicians Surg Pak 2018; 28(4):292-6. doi: 10.29271/ jcpsp.2018.04.292.

4. Mantovani A, Allavena P, Sica A, Balkwill F. Cancer-related inflammation. Nature 2008; 454(7203):436-444. doi: 10. 1038/nature07205.

5. Ozer J, Ratner M, Shaw M, Bailey W, Schomaker S. The current state of serum biomarkers of hepatotoxicity. Toxicology 2008; 245(3):194-205. doi: 10.1016/j.tox.2007. 11.021.

6. De Ritis F, Coltorti M, Giusti G. An enzymic test for the diagnosis of viral hepatitis; the transaminase serum activities. Clin Chim Acta 1957; 2(1):70-4. doi: 10.1016/ 0009-8981(57)90027-x.

7. Bezan A, Mrsic E, Krieger D, Stojakovic T, Pummer K, Zigeuner $\mathrm{R}$, et al. The preoperative AST/ALT (De Ritis) ratio represents a poor prognostic factor in a cohort of patients with nonmetastatic renal cell carcinoma. J Urol 2015; 194(1):30-5. doi: 10.1016/j.juro.2015.01.083.

8. Lee $H$, Choi $Y H$, Sung $H H$, Han DH, Jeon HG, Jeong BC, et al. De Ritis Ratio (AST/ALT) as a significant prognostic factor in patients with upper tract urothelial cancer treated with surgery. Clin Genitourin Cancer 2017; 15(3):e379-e385. doi: 10.1016/j.clgc.2016.08.023.

9. Guner E, Seker KG, Arikan Y, Huseynov C, Sam E, Ozdal $\mathrm{OL}$. The utility of De Ritis Ratio in predicting prognosis in testicular cancer. Aktuelle Urol 2020; 51(3):285-9. doi: 10.1055/a-1117-2776.

10. Gorgel SN, Akin Y, Koc EM, Kose O, Ozcan S, Yilmaz Y. Impact of increased aspartate aminotransferase to alanine aminotransferase (De Ritis) ratio in prognosis of testicular cancer. Investig Clin Urol 2019; 60(3):169-175. doi: 10.4111/icu.2019.60.3.169.

11. Karamık K, Aktaş Y, Yıldız A, Erol I, İslamoğlu E, Ateş M, et al. Predictive role of de ritis ratio in biochemical recurrence after radical prostatectomy. Med Bull Haseki 2020; 58. DOI: 10.4274/haseki.galenos.2019.5592

12. Brierley JD, Gospodarowicz MK, Wittekind C. TNM classification of malignant tumours. 8th ed: John Wiley \& Sons; 2017.

13. Stulting RD, Berke G. Nature of lymphocyte-tumor interac- 
tion. A general method for cellular immuno-absorption. J Exp Med 1973; 137(4):932-42. doi: 10.1084/jem. 137. 4.932.

14. Arda E, Arikan G, Akdere H, Akgul M, Yuksel I. Predictive and prognostic impact of preoperative complete blood count based systemic inflammatory markers in testicular cancer. Int Braz J Urol 2020; 46(2):216-23. doi: 10.1590/ S1677-5538.IBJU.2018.0820.

15. Gokcen K, Dundar G, Gulbahar H, Gokce G, Gultekin EY. Can routine peripheral blood counts like neutrophil-to-lymphocyte ratio be beneficial in prediagnosis of testicular cancer and its stages? J Res Med Sci 2018; 23:64. doi: 10.4103/jrms.JRMS_1009_16

16. Çalışkan S, Kaba S, Özsoy E, Koca O, Akyüz M, Öztürk Mi. The hematological parameters in testicular cancer. J Oncol Sci 2017; 3(3):117-119. doi.org/10.1016/j.jons.2017. 10.002 .

17. Yuksel OH, Verit A, Sahin A, Urkmez A, Uruc F. White blood cell counts and neutrophil to lymphocyte ratio in the diagnosis of testicular cancer: A simple secondary serum tumor marker. Int Braz J Urol 2016; 42(1):53-59. doi: 10.1590/S1677-5538.IBJU.2014.0593.

18. Ilktac A, Dogan B, Ersoz C, Akcay M, Akbulut H. The relationship of neutrophil to lymphocyte ratio with testicular cancer. Int Braz J Urol 2020; 46(1):101-107. doi: 10.1590/S1677-5538.IBJU.2019.0321.

19. Herraiz-Raya L, Moreillo-Vicente L, Martinez-Ruiz J, Martínez AA, Anguita PJF, Rueda JAE, et al. Leukocyte and platelet counts as prognostic values of testicular germ cell tumours. Actas Urol Esp 2019; 43(6):284-92. doi: 10.1016/j.acuro.2019.02.002.

20. Bolat D, Aydogdu O, Polat S, Yarimoglu S, Bozkurt IH, Yonguç $\mathrm{T}$, et al. Predictive value of preoperative neutrophil-to-lymphocyte ratio on the prognosis of germ cell testicular tumors. Turk J Urol 2017; 43(1):55-61. doi: 10.5152/tud.2016.38924.

21. Olcucu MT, Karamik K, Yilmaz K, Ozsoy C, Aktas Y, Ates M. Preoperative inflammation markers in predicting biochemical recurrence after robot-assisted radical prostatectomy. J Coll Physicians Surg Pak. 2020 Sep; 30(9):921-927. doi: 10.29271/jcpsp.2020.09.921

22. Nishijima TF, Muss HB, Shachar SS, Tamura K, Takamatsu Y. Prognostic value of Iymphocyte-to-monocyte ratio in patients with solid tumors: A systematic review and meta-analysis. Cancer Treat Rev 2015; 41(10):971-978. doi: 10.1016/ j.ctrv.2015.10.003.

23. Li J, Cheng Y, Ji Z. Prognostic value of pretreatment lymphocyte-to-monocyte ratio in patients with urologic tumors: A PRISMA-compliant meta-analysis. Medicine (Baltimore) 2019; 98(2):e14091. doi: 10.1097/MD. 00000 00000014091.

24. Conde VR, Oliveira PF, Nunes AR, Ocha CS, Ramalbosa E, Pereira JA, et al. The progression from a lower to a higher invasive stage of bladder cancer is associated with severe alterations in glucose and pyruvate metabolism. Experimental cell research 2015; 335(1):91-98. doi: 10.1016/j. yexcr.2015.04.007. 